\title{
Lisch epithelial corneal dystrophy
}

INSERM

\section{Source}

INSERM. (1999). Orphanet: an online rare disease and orphan drug data base. Lisch epithelial corneal dystrophy. ORPHA:98955

Lisch epithelial corneal dystrophy (LECD) is a very rare form of superficial corneal dystrophy characterized by feather-shaped opacities and microcysts in the corneal epithelium arranged in a band-shaped and sometimes whorled pattern, occasionally with impaired vision. 